\title{
Article \\ Characterization of Molecular Properties and Expression of Gene GmPLMT and Its Effects on the Production of Lipid Metabolites in Soybean and Arabidopsis thaliana
}

\author{
Zhanyu Chen ${ }^{1}$, Yushuang Wang ${ }^{1}$, Yanbo Chen ${ }^{2}$, Xiaoqin Yang ${ }^{2}$, Shuang Wang ${ }^{2}$, Tingting Yu ${ }^{3} \oplus$, Ying Zhou ${ }^{2, *}$ \\ and Xiyan Cui ${ }^{2, *(D)}$ \\ 1 College of Agronomy, Jilin Agricultural University, Changchun 130118, China; zhanyuc@jlau.edu.cn (Z.C.); \\ 20200026@mails.jlau.edu.cn (Y.W.) \\ 2 College of Life Sciences, Jilin Agricultural University, Changchun 130118, China; \\ 1911200421@mails.jlau.edu.cn (Y.C.); 20211235@mails.jlau.edu.cn (X.Y.); 20150405@mails.jlau.edu.cn (S.W.) \\ 3 Key Laboratory of Molecular Epigenetics of the Ministry of Education, Northeast Normal University, \\ Changchun 130024, China; yutt945@nenu.edu.cn \\ * $\quad$ Correspondence: yzhou@jlau.edu.cn (Y.Z.); cuixiyan@jlau.edu.cn (X.C.); Tel.: +86-431-8453-3182 (X.C.)
}

check for updates

Citation: Chen, Z.; Wang, Y.; Chen, Y.; Yang, X.; Wang, S.; Yu, T.; Zhou, Y.; Cui, X. Characterization of Molecular Properties and Expression of Gene GmPLMT and Its Effects on the Production of Lipid Metabolites in Soybean and Arabidopsis thaliana. Agronomy 2021, 11, 2454. https:/ / doi.org/10.3390/agronomy11122454

Academic Editor: Fabio Fiorani

Received: 13 November 2021 Accepted: 29 November 2021 Published: 1 December 2021

Publisher's Note: MDPI stays neutral with regard to jurisdictional claims in published maps and institutional affiliations.

Copyright: (c) 2021 by the authors. Licensee MDPI, Basel, Switzerland. This article is an open access article distributed under the terms and conditions of the Creative Commons Attribution (CC BY) license (https:/ / creativecommons.org/licenses/by/ $4.0 /)$.

\begin{abstract}
Phospholipid N-methyltransferase (PLMT) plays an important role in the synthesis of phosphatidylcholine (PtdCho). The aim of this study was to characterize the molecular properties of GmPLMT and the expression of soybean GmPLMT and its effects on the production of lipid metabolites. Results showed that GmPLMT composed of mainly $\alpha$-helix was a hydrophobic and transmembrane protein. In soybean leaves, GmPLMT was highly expressed during seedling and flowering stages. In transgenic Arabidopsis thaliana, the highest and lowest expression levels of GmPLMT were detected at flowering and maturity stages, respectively. The total phospholipid contents in soybean grains were decreased from $7.2 \%$ (35 days after flowering) to $4.8 \%$ (55 days after flowering) and then increased to $7.0 \%$ (75 days after flowering). The contents of PtdCho showed a similar pattern to that of total phospholipids. In transgenic $A$. thaliana seeds, the contents of total phospholipids and PtdCho were significantly increased. Significantly positive correlations were revealed between expression of GmPLMT and contents of both PtdCho and crude fats, and between the contents of PtdCho and both linoleic acid and linolenic acid, suggesting that increased expression of GmPLMT improved the production of lipid metabolites. This study provided solid experimental evidence for further improvement of soybean quality based on GmPLMT in the molecular breeding of soybeans.
\end{abstract}

Keywords: phospholipid compounds; GmPLMT; lipid metabolism; soybean; Arabidopsis

\section{Introduction}

Soybean is an important crop for both food and oil, providing a large amount of high-quality nutrients such as proteins and phospholipids. Soybean grains are rich in fats and proteins, and the contents of fatty acids in the grains account for more than $90 \%$ of the total oil. Among the fatty acids, two types of unsaturated fatty acids (i.e., linoleic acid and linolenic acid) not synthesized by humans and other mammals are necessary for normal growth and development. The phospholipids are the fundamental materials of life and are important structural components of cell membranes in tissues of both humans and other animals $[1,2]$. As the indispensable substances for maintaining normal metabolism and the healthy human body, phospholipids are mainly obtained from soybeans. Soybean phospholipids can not only regulate the activities of enzymes related to membrane functions, but also control the information and substances inside and outside the cell membrane. For example, unsaturated fatty acids in soybean phospholipids improve the functions of biofilm [3]. Soybean phospholipids also improve the antioxidant activities and enhance 
the nutritional functions of the body [3]. As the main components of phospholipids, both the phosphatidylcholine (PtdCho) and phosphatidylethanolamine (PtdEtn) are important metabolites for plant growth and development, and as the main lipid components of the plant cell membrane, these two types of metabolites account for $40-60 \%$ of the total phospholipids [4,5]. PtdCho has also been used as a type of nutritional additive to provide the phospholipids needed in animals to improve the immunity and survival rate of pups [6]. As one of the important sources of plant proteins and edible oil, the content of PtdCho is commonly used as an important indicator to assess the quality of soybeans. Furthermore, as a type of raw natural material, soy lecithin is mainly composed of PtdCho and is widely used in food, medicine, and cosmetic industries [7]. Furthermore, PtdCho is a major membrane phospholipid and a precursor for several major signaling molecules. Therefore, understanding the biosynthesis of PtdCho is important for improving plant growth, nutritional value, and resistance to stress [8].

In recent years, the separation, extraction, and biological functions of phospholipids have been extensively investigated. For example, studies have shown that the yields of lipids and phospholipids using subcritical dimethyl ether are higher than those based on propane and its mixed solvents, while the biological functions of the asymmetric distribution of phospholipids in cell membranes have been well explored [9-11]. However, studies on the functions of the gene encoding phosphatidyl methyltransferase (PLMT) at genetic level are sparsely reported in plants, whereas studies have shown that the PLMTs in animals and yeast catalyze the methylation of PtdEtn to generate PtdCho in vivo [12,13]. Furthermore, fundamental differences have been revealed between the biosynthetic pathways of PtdCho in yeast and plants [14]. The PLMT was cloned for the first time in both Arabidopsis thaliana and soybean, while studies have further shown that AtPLMT is involved in the PtdCho metabolic pathway of $A$. thaliana [15]. Furthermore, as the key enzymes for PtdCho synthesis in A. thaliana, two isoforms (i.e., PMT1 and PMT3) of phospho-base Nmethyltransferase (PMT) are the primary enzymes for the biosynthesis of phosphocholine, which is involved in the PtdCho biosynthesis and vascular development in A. thaliana seedlings [16]. Moreover, it has been reported that the soybean phosphoethanolamine methyltransferase (PEAMT) genes play an important role in PtdCho synthesis [17]. As the biosynthetic precursor of glycine betaine, PtdCho is an osmotic protective agent commonly found in plants to increase the osmotic pressure in the cytoplasm, protect plant cell membranes under stressed conditions, and keep their lipid membranes intact [18-20]. Studies have shown that the genetic engineering technology based on PLMTs can not only increase the contents of PtdCho in transgenic plants, but also improve plant resistance to abiotic stresses [21]. To date, comprehensive studies on the explicit functions of PLMTs in plants are still lacking.

In this study, the molecular characteristics and expression patterns of GmPLMT in soybean and transgenic $A$. thaliana were investigated. The correlation between the gene expression of GmPLMT and both physiological and biochemical indices related to lipid metabolisms were further analyzed, and the effects of GmPLMT on the production of various types of lipid metabolites were also explored. The results showed that transgenic GmPLMT gene promoted the growth and development of $A$. thaliana, and the expression of GmPLMT regulated the contents of lipid metabolites in soybean grains and the seeds of transgenic $A$. thaliana. This study provided the solid experimental foundation for further studies of the functions of PLMT gene in other plants and identified GmPLMT as the candidate gene for genetic engineering to further improve the quality of soybean.

\section{Materials and Methods}

\subsection{Plant Materials}

The high-oil variety "Jiyu 72" of soybean [Glycine max (L.) Merr.] provided by the Jilin Academy of Agricultural Sciences (Changchun, China) was planted in the Teaching and Scientific Research Station of the Jilin Agricultural University in Changchun, China $\left(43.5^{\circ} \mathrm{N}, 125.1^{\circ} \mathrm{E}\right)$ in a total of 10 rows each of $5 \mathrm{~m}$ in length, row spacing $0.65 \mathrm{~m}$, density 
200,000 plants $/ \mathrm{hm}^{2}$, and repeated three times. The expression levels of GmPLMT were measured in soybean leaves at different developmental stages (i.e., seedling, branching, flowering and podding, filling, and maturity stages). Starting from the 35th day after flowering, the pods at the top of soybean plants were collected every five days for a total of nine samples (i.e., T1-T9) to measure the expression levels of GmPLMT and the contents of main products generated in lipid metabolism.

Columbia type (Col-0) of Arabidopsis thaliana (L.) Heynh. was used as wild type (WT) for genetic transformation of GmPLMT. Plants of A. thaliana was grown in the artificial climate room of the School of Life Sciences of Jilin Agricultural University with a photoperiod cycle of 12-h light and 12-h dark, a temperature of $22{ }^{\circ} \mathrm{C}$, and a relative humidity of $50 \%$. Flower buds at the top of the stem were treated with Agrobacterium tumefaciens EHA105 with transformed GmPLMT. The seeds collected were sprayed with $1 \%$ glyphosate solution and were repeatedly screened to generate $\mathrm{T} 3$ generation. The transgenic plants of $A$. thaliana in T3 generation were sampled in four developmental stages (i.e., four-leaf, bolting, flowering, and maturity stages), with the WT of $A$. thaliana used as the control.

\subsection{Molecular Properties of GmPLMT}

In the previous studies, primers were designed based on the GmPLMT sequence (NM_001249156.2) retrieved from the National Center for Biotechnology Information (NCBI; https: / / www.ncbi.nlm.nih.gov/, accessed on 1 January 2018) database to obtain the GmPLMT sequence of $627 \mathrm{bp}$ and to investigate its gene expression under salt and alkali stresses [22]. In this study, DNAMAN software was used to comparatively analyze seven protein sequences of PLMT, including Schizosaccharomyces pombe (AF004112.1), A. thaliana (NP_565246.1), Glycine max (NM_001249156.2), Brassica napus (XP_013674943.1), Arachis ipaensis (XP_016176048.1), Cannabis sativa (KAF4387675.1), and Zea mays (PWZ27952.1). The molecular properties, functional domains, and tertiary structures of GmPLMT were predicted by SMART (http: / / smart.embl-heidelberg.de/, accessed on 1 May 2020). The relative molecular weight and theoretical isoelectric point of GmPLMT were calculated by ProtParam [23]. The hydrophobicity of GmPLMT was analyzed by ProtScale with the secondary structure predicted by NetSurfP-2.0 at SOPMA [24], the signal peptide predicted by SingaIP [25], and the transmembrane domain predicted by PSIPRED4.0 [26].

\subsection{Construction of Plant Expression Vector of GmPLMT and Its Genetic Transformation in Arabidopsis thaliana}

The CDS sequence (504 bp) of GmPLMT containing both the HindIII and BamHI restriction sites was PCR-amplified by using the recombinant plasmid of GmPLMT as template and primers MQGmPLMT-A (5'-CGCGGATCCATGGGGATTGCGGCGGCTAT$\left.3^{\prime}\right)$ and MQGmPLMT-S (5'-CCCAAGCTTTCAATGGAGTGGCTTGGCACG-3') with the PCR conditions as follows: pre-denaturation at $95^{\circ} \mathrm{C}$ for $5 \mathrm{~min}$, followed by 35 cycles of "denaturation at $94{ }^{\circ} \mathrm{C}$ for $30 \mathrm{~s}$, annealing at $54{ }^{\circ} \mathrm{C}$ for $40 \mathrm{~s}$, extension at $72{ }^{\circ} \mathrm{C}$ for $2.5 \mathrm{~min}$ ", and final extension at $72{ }^{\circ} \mathrm{C}$ for $15 \mathrm{~min}$. The GmPLMT fragment was digested with HindIII and BamHI (Takara Biotechnology Co., Ltd., Dalian, China) and ligated with T4DNA ligase into the plant expression vector pCAMBIA 3301, which was then transformed into Escherichia coli DH5 $\alpha$. The successful transformation was verified by PCR and double restriction endonuclease digestion of HindIII and BamHI. The positive clones were sent to the Shanghai Shenggong Bioengineering Co., Ltd. (Shanghai, China) for sequencing. The plant expression vector containing GmPLMT gene was successfully constructed and named pCAMBIA3301-GmPLMT, and the E. coli DH5 $\alpha$ containing the recombinant plasmid was cryopreserved for further experiments. Then, the plant expression vector pCAMBIA3301-GmPLMT was transformed into the Agrobacterium tumefaciens EHA105 by triparental hybridization method [27], with the successful transformation verified by PCR. During the flowering stage, plants of $A$. thaliana were infected with Agrobacterium tumefaciens using the inflorescence infection method [28]. 


\subsection{Detection of Copy Number of GmPLMT in Transgenic Plants of Arabidopsis thaliana by Southern Blotting}

Plants of transgenic $A$. thaliana of T3 generation were selected to detect the copy number of GmPLMT by southern blotting [29]. The genomic DNA was digested with EcoRI endonuclease for $2 \mathrm{~h}$ with the products $(15 \mu \mathrm{L})$ run on $1 \%$ agarose electrophoresis gel for $4 \mathrm{~h}$. The digested fragments were transferred to the nylon membrane using the downward transfer method [30]. The probes were prepared and hybridized using the Dig High Prime DNA Labeling \& Detection Starter Kit according to the manufacturer's instructions (Roche, Basel, Switzerland). The hybridization reaction was set to temperature at $42{ }^{\circ} \mathrm{C}$, with the membrane washed twice with $2 \times$ saline sodium citrate (SSC) buffer at $37^{\circ} \mathrm{C}$ for $15 \mathrm{~min}$ and then twice with $0.5 \times$ SSC buffer at $66^{\circ} \mathrm{C}$ for $15 \mathrm{~min}$. BCIP/NBT (Thermo Fisher Scientific Co., Ltd., Shanghai, China) was used to develop the chemical color on the nylon membrane.

\subsection{Determination of Gene Expression of GmPLMT}

The qPCR was carried out to determine the expression of GmPLMT using the All-inOne ${ }^{\mathrm{TM}}$ qPCR Mix Kit (Takara Biotechnology Co., Ltd., Dalian, China) according to the manufacturer's instructions with the reaction set up at follows: the cDNAs of soybean and $A$. thaliana at different developmental stages were used as templates, primers YGGmPLMTF (5'-CAGTACGTTGGCAGCATCAT- $\left.3^{\prime}\right)$ and YGGmPLMT-R (5'-GTGGCTTGGCACGAGTAGAT-3') for target gene GmPLMT, and primers ElF1B-F (5'-CTGGTTCCTGTGGGATATGG$\left.3^{\prime}\right)$ and ElF1B-R (5'-TACTCGTTGCATGGCTCAAC-3') for internal reference gene ElF1B. All experiments were repeated with three replicates. The relative expression was calculated based on the average cycle threshold $(\mathrm{Ct})$ value and the $2^{-\Delta \Delta \mathrm{Ct}}$ method [31].

\subsection{Determination of Physiological and Biochemical Indices Related to the Phospholipid Metabolism}

The phospholipid content was determined by the molybdenum blue colorimetric method [32]. Specifically, $1 \mathrm{~g}$ of powder sample was added with $20 \mathrm{~mL}$ Folch reagent (chloroform:methanol $=2: 1$ ) for extraction under ultrasound for $1 \mathrm{~h}$, with the reduced solvent replenished and the supernatant collected. The supernatant $(0.1 \mathrm{~mL})$ was first evaporated in a water bath at $40{ }^{\circ} \mathrm{C}$, added with a suppressant $(70 \%$ perchloric acid, $0.25 \mathrm{~mL}$ ) until the liquid became colorless, and then after cooling, volumed to $5 \mathrm{~mL}$ using a phosphorus chromogenic agent ( $3 \mathrm{~mol} / \mathrm{L} \mathrm{H}_{2} \mathrm{SO}_{4}$ :water: $2.5 \%$ ammonium molybdate: $10 \%$ ascorbic acid $=1: 5: 1: 1)$ to determine the absorbance at $700 \mathrm{~nm}$. The total phospholipid content was calculated according to the standard curve generated based on regression equation, and the phospholipid content was obtained by multiplying the phospholipid conversion coefficient 25 .

The contents of PtdCho and PtdEtn were determined by the solvent extraction method [33]. Specifically, $1 \mathrm{~g}$ of powder sample was added with $10 \mathrm{~mL}$ acetone to shake in a water bath for $3 \mathrm{~h}$, extracted with ethanol, and the extract was evaporated and concentrated by rotary evaporator to obtain yellow paste phospholipids. The crude sample was dissolved with ether, filtered, and dried to obtain PtdCho. The insoluble substances extracted by ethanol were repeatedly extracted with petroleum ether five times, with the solution combined, distilled, and concentrated to $10 \mathrm{~mL}$, which was washed and precipitated with an equal amount of ethanol, filtered, and dried to generate PtdEtn shown as yellowish powder. These experiments were repeated with three replicates.

The contents of palmitic acid, stearic acid, oleic acid, linoleic acid, and linolenic acid were determined by gas chromatography [34]. The powder sample $(0.1 \mathrm{~g})$ was added with $2 \mathrm{~mL}$ sodium methoxide $(0.5 \mathrm{~mol} / \mathrm{L})$ to esterify for $30 \mathrm{~min}$ in a water bath at $30{ }^{\circ} \mathrm{C}$, and extracted twice with $10 \mathrm{~mL}$ n-hexane. The relative contents of fatty acid components were determined by Thermo Trace 1300 gas chromatography (Thermo Fisher Scientific Co., Ltd., Shanghai, China) with the chromatographic column of RTX-Wax 
$(100 \mathrm{~m} \times 0.25 \mathrm{~mm} \times 0.2 \mu \mathrm{m})$, the hydrogen flame ion detector (FID), and the temperature set at $300^{\circ} \mathrm{C}$.

The content of crude fats was determined by the Soxhlet extraction method [34]. The powder sample of $1 \mathrm{~g}$ was wrapped in filter paper and put into the fat analyzer (SZCC, Shanghai Fiber Inspection Instrument Co., Ltd., Shanghai, China) for extraction with $60 \mathrm{~mL}$ ether at $60^{\circ} \mathrm{C}$ for $2 \mathrm{~h}$ to make the ether reflux until the ether in the extraction tube was volatilized with no oil stain. After extraction, the crude fats were weighed, and the content of crude fats in the dry weight of the sample was calculated.

Correlation analysis was conducted between the expression of GmPLMT and the contents of lipid metabolites in soybean grains at different stages of maturity using SPSS 22 (SPSS Inc., Chicago, IL, USA).

\section{Results and Discussion}

\subsection{Bioinformatics Analysis of GmPLMT Gene and Its Encoded Protein in Soybean}

Comparative analysis of seven PLMT sequences, including Schizosaccharomyces pombe, A. thaliana, Glycine max, Brassica napus, Arachis ipaensis, Cannabis sativa, and Zea mays, based on DNAMAN software, showed that the overall similarity of the seven proteins was $59.2 \%$, with a similarity of $81.5 \%$ among the six species of plants, indicating that the plant PLMT proteins were relatively conservative in evolution. The soybean protein GmPLMT with a molecular formula $\mathrm{C}_{956} \mathrm{H}_{1363} \mathrm{~N}_{213} \mathrm{O}_{221} \mathrm{~S}_{8}$ encoded by GmPLMT contained a total of 167 amino acids, with a molecular weight of $19.632 \mathrm{KDa}$, the theoretical isoelectric point of 8.75 , and Phe accounted for the highest proportion (10.2\%) and Ala the least proportion $(0.6 \%)$ among the 20 amino acids. The GmPLMT was classified as an unstable protein based on the instability index (II) value of 42.10 , with the grand average coefficient of total hydropathicity (GRAVY) of 0.386 .

Results of the hydrophobicity analysis of the predicted GmPLMT by ProtScale showed that the Val located at position 144 was the most hydrophobic amino acid with a score of 2.411 and the Asp at position 158 was the most hydrophilic with a score of -2.533 (Figure 1). Overall, the amino acids at positions $26-41$ and 153-163 showed strong hydrophilicity with the hydrophobic amino acids largely evenly distributed in the entire peptide chain. These results suggested that the GmPLMT was a type of hydrophobic protein, which was consistent with the predicted value of GRAVY.

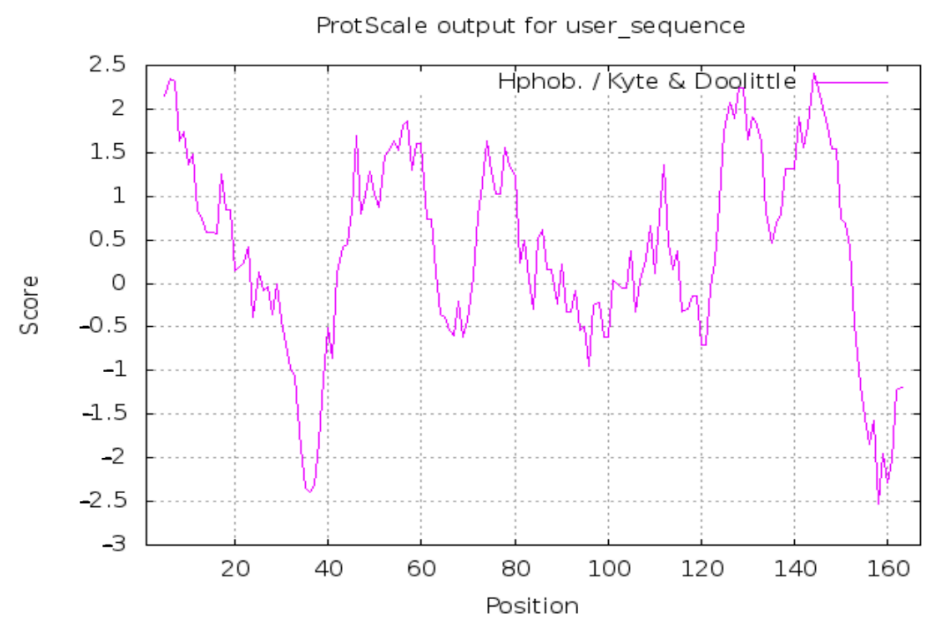

Figure 1. Hydrophobicity and hydrophilicity of soybean GmPLMT predicted by ProtScale.

The predicted secondary structure of GmPLMT based on NetSurfP-2.0 showed that $\alpha$-helix accounted for the large portion of the entire protein $(68.9 \%)$ and $\beta$-corner accounted for $29.9 \%$, with no signal peptide identified (Figure 2). A total of four transmembrane regions were identified by PSIPRED4.0 in the amino acid sequence of GmPLMT, which was classified as a type of transmembrane protein with its $\mathrm{N}$-terminal and C-terminal located 
outside the plasma membrane (Figure 3). These results were consistent with those reported previously based on S. pombe [35].

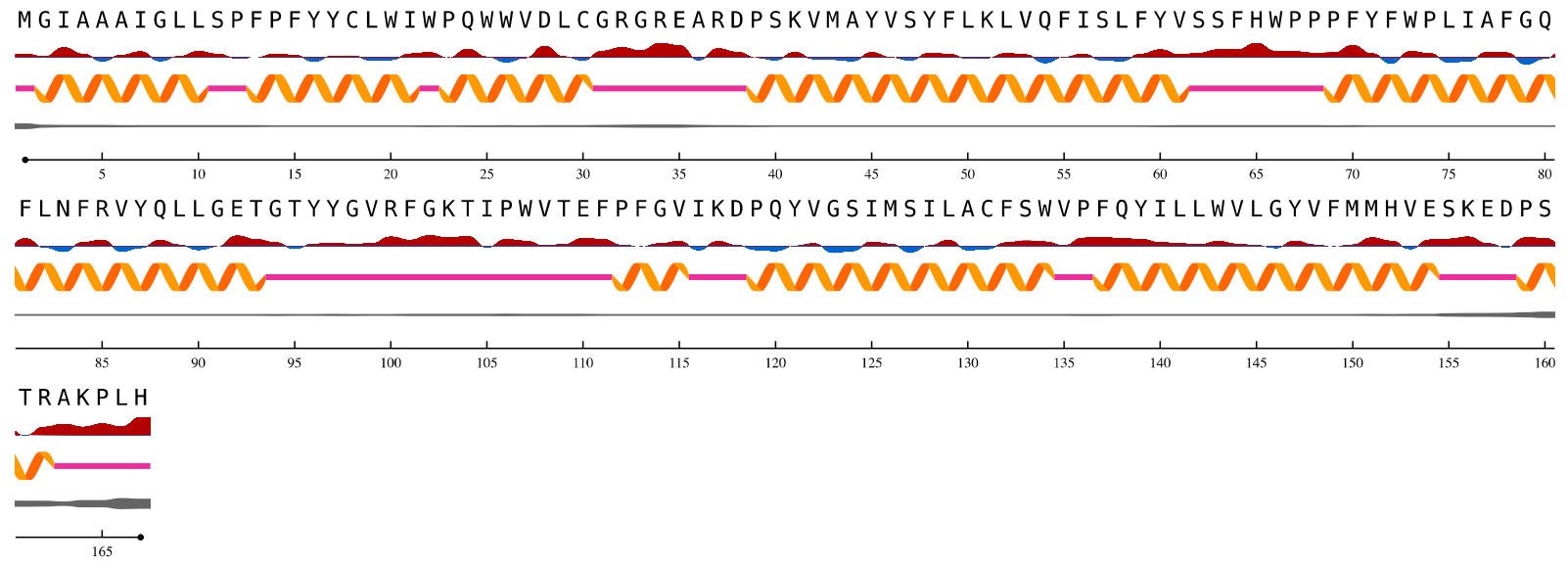

Figure 2. Secondary structure of soybean GmPLMT predicted by NetSurfP-2.

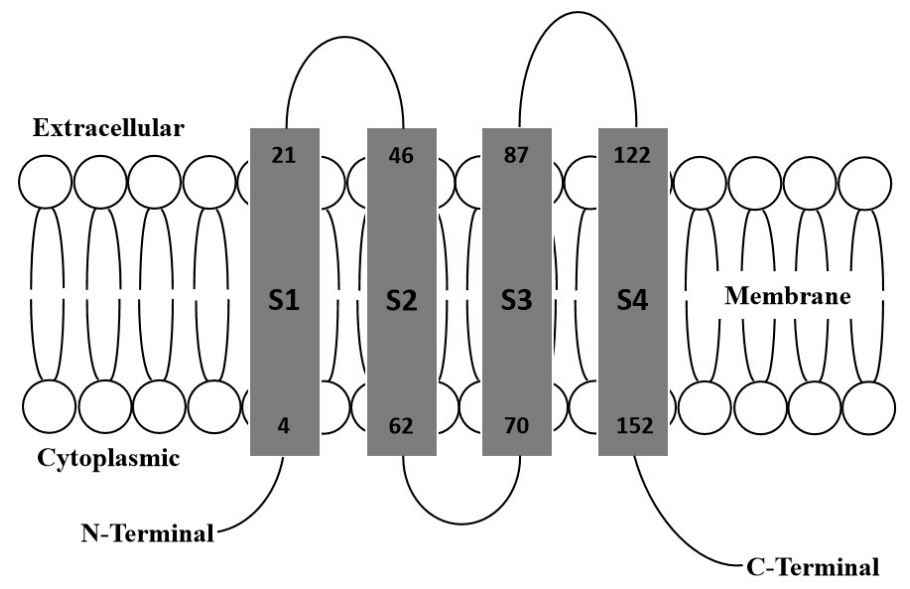

Figure 3. Transmembrane domains (S1-S4) of soybean GmPLMT predicated by PSIPRED4.0.

The three-dimensional structure of the protein encoded by GmPLMT predicted based on SMART showed that GmPLMT contained a S-adenosyl-L-methionine (SAM) binding domain which was consistent with the structural properties of methyltransferases (Figure 4), evidently indicating that GmPLMT was a member of the methyl-transferring proteins. Studies have shown that methyltransferases are widely involved in many important cellular processes in plants, including biosynthesis, signal transduction, protein repair, and chromatin regulation [36,37]. Further studies are necessary to identify the explicit biological functions of GmPLMT in plants.
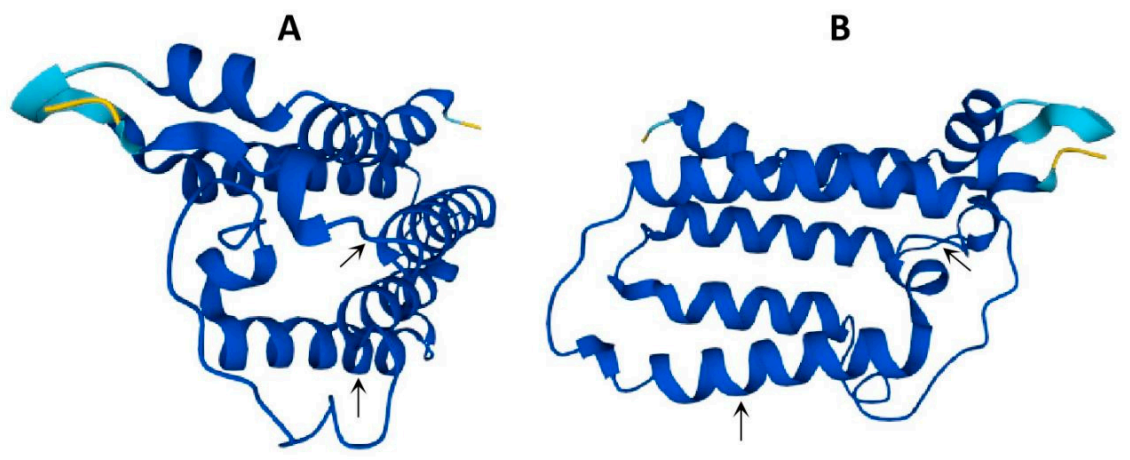

Figure 4. Tertiary structure of soybean GmPLMT shown in XY plan (A) and XZ plan (B) predicted by SMART. 
The sequence alignments of seven PLMT proteins (i.e., Schizosaccharomyces pombe, soybean, A. thaliana, Brassica napus, Arachis ipaensis, Cannabis sativa, and Zea mays) were presented in Figure 5. Results showed that the middle portion of GmPLMT was a relatively conserved region, representing a possibly conserved functional domain, i.e. presumably the phospholipid binding site, while the tripeptide AFG and dipeptide ED were the domains of the SAM binding site $[15,35]$. The PLMTs are involved in the synthesis of PtdCho to transfer a methyl group from SAM to a nucleophilic acceptor, such as oxygen, ultimately generating S-adenosyl-L-homocysteine and a methylated molecule [38]. Results in the current study showed that the amino acid sequence of GmPLMT contained two SAM binding domains, with one composed of 3 amino acids located at positions 77-79 and the other of 2 amino acids located at positions 157 and 158. It has been suggested that all methyltransferases, including those catalyzing the methylation of DNAs, proteins, RNAs, and lipids, contain a tripeptide SAM binding site GXG [39]. Furthermore, studies have revealed tripeptide CFG in the PLMT protein of S. pombe [35]. However, the results in the current study identified the tripeptide AFG in six species of plants, including both soybean and $A$. thaliana. These results suggested that the variations in the structural domain of the SAM binding site in plants caused the differentiated functions of PLMTs. These results were consistent with the structural characteristics of methyltransferases [40,41]. Further investigations are necessary to verify these discoveries revealed in the current study.

Schizosaccharomyces pombe
Glycine max
Arabidopsis thaliana
Brassica napus
Arachis ipaensis
Cannabis sativa
Zea mays
Consensus

Schizosaccharomyces pombe Glycine max

Arabidopsis thaliana

Brassica napus

Arachis ipaensis

Cannabis sativa

Zea mays

Consensus

Schizosaccharomyces pombe
Glycine max
Arabidopsis thaliana
Brassica napus
Arachis ipaensis
Cannabis sativa
Zea mays
Consensus

Schizosaccharomyces pombe Glycine max

Arabidopsis thaliana

Brassica napus

Arachis ipaensis

Cannabis sativa

Zea mays

Consensus
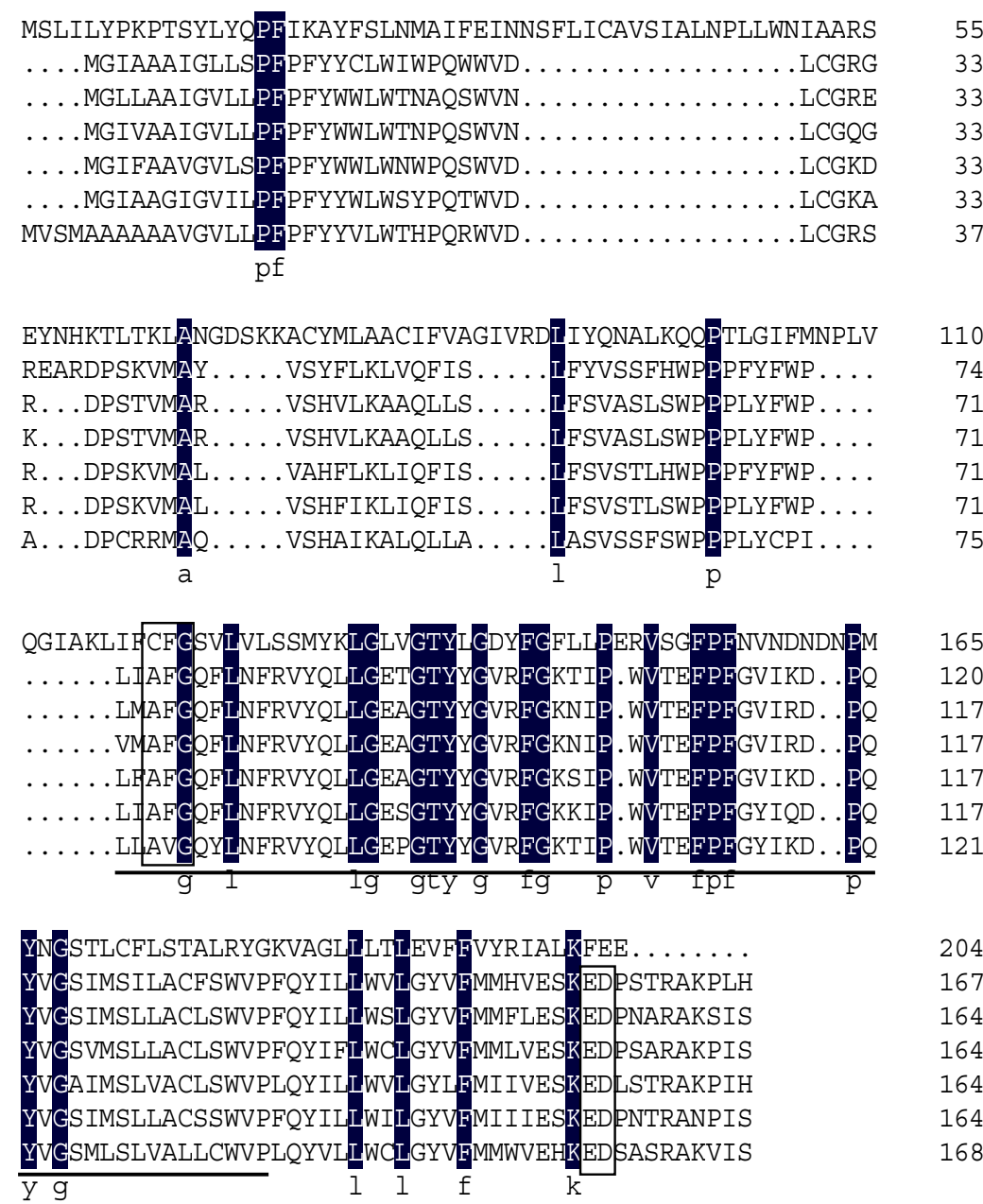

204

167

164

164

164

164

168

Figure 5. Sequence alignments of seven phospholipid methyltransferase (PLMT) proteins including Schizosaccharomyces pombe (AF004112.1), Glycine max (NM_001249156.2), Arabidopsis thaliana (NP_565246.1), Brassica napus (XP_013674943.1), Arachis ipaensis (XP_016176048.1), Cannabis sativa (KAF4387675.1), and Zea mays (PWZ27952.1). The conserved amino acids among the PLMTs are indicated by a dark background. The underlined regions represent the predicted phospholipid binding sites. The proposed binding sites (i.e., AFG and ED) for S-adenosyl-L-methionine (SAM) are indicated by two boxes. 


\subsection{Genetic Transformation of GmPLMT in Arabidopsis thaliana}

\subsubsection{Construction of Plant Overexpression Vector of pCAMBIA 3301-GmPLMT}

The primers with restriction sites of HindIII and BamHI were used to PCR-amplify the GmPLMT based on plasmid pCAMBIA3301-GmPLMT (Figure 6A). The $504 \mathrm{bp}$ fragment of GmPLMT was successfully cloned, ligated with T4 DNA ligase, and transformed into the plant expression vector pCAMBIA3301 to successfully construct the pCAMBIA3301GmPLMT recombinant plasmid, which was verified by PCR and double restriction endonuclease digestion of HindIII and BamHI (Figure 6B).

A

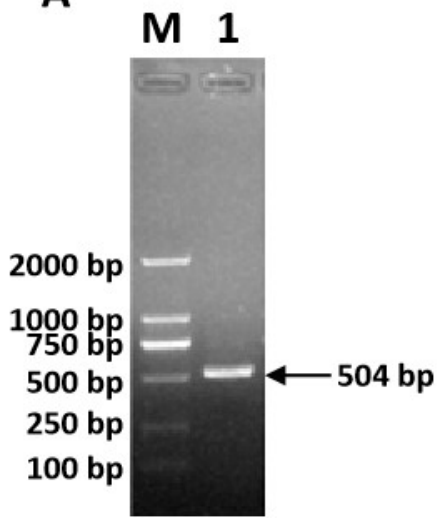

B

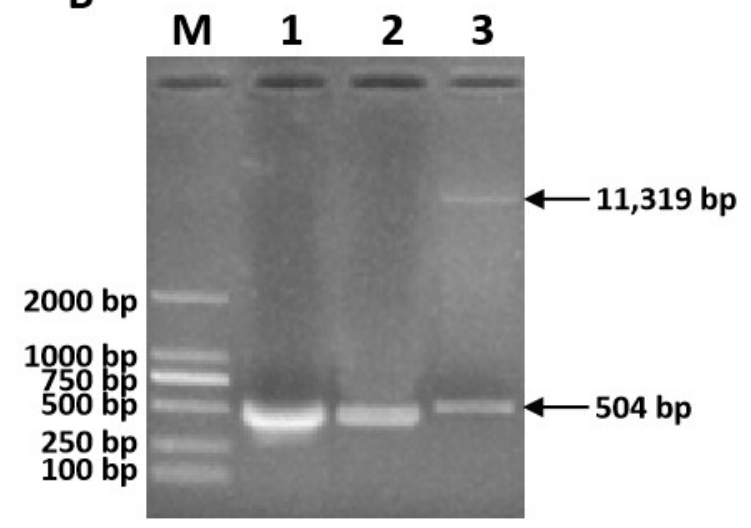

Figure 6. Construction and verification of recombinant plasmid pCAMBIA3301-GmPLMT based on PCR (A) and double restriction endonuclease digestion of HindIII and BamHI (B). Lane M represents DL2000 DNA marker. Lane 1 in (A) indicates GmPLMT of 504 bp. Lanes 1-3 in (B) represent the PCR product based on the recombinant plasmid pCAMBIA3301-GmPLMT (GmPLMT of $504 \mathrm{bp}$ ), the bacterial liquid PCR product (GmPLMT of $504 \mathrm{bp}$ ), and the products of the double restriction endonuclease digestion of plasmid based on HindIII and BamHI (504 bp of GmPLMT and 11,319 bp of the plasmid).

The pCAMBIA3301-GmPLMT recombinant plasmids were successfully transformed into Agrobacterium tumefaciens EHA105 by the triparental hybridization method, as verified by PCR and the sequence of the target gene showing $100 \%$ identity as that of the sequence of GmPLMT (NM_001249156.2) retrieved from the NCBI database.

3.2.2. Phenotypic Comparison and Southern Blotting Detection of Transgenic Arabidopsis thaliana with GmPLMT

In this study, the GmPLMT gene was overexpressed in A. thaliana with the goal to further understand the explicit effects of soybean PLMT on the lipid metabolism. The results of the southern blotting hybridization of GmPLMT in transgenic A. thaliana showed that GmPLMT was integrated into the genome of $A$. thaliana as a single copy (Figure 7). Phenotypic observations were regularly made on the seedlings of WT (control) and transgenic plants of $A$. thaliana in T3 generation, showing evidently phenotypic differentiation (i.e., increased biomass) in the mature transgenic plants of $A$. thaliana in comparison to the WT plants. The transgenic plants of $A$. thaliana were larger, with larger and more leaves than WT plants. In comparison to the WT plants, the number of leaves was increased by $48.6 \%$, the plant height increased by $39.2 \%$, and the root length increased by $20.4 \%$ in the transgenic plants. Furthermore, in transgenic plants, the number of pods was increased by $31.8 \%$ and the length of pods was increased by $18.1 \%$ compared with those of the WT plants. Moreover, the seed size in the transgenic plants was larger than that of the WT plants. These results were consistent with those reported previously, showing that the overexpression of genes led to enhanced growth in plants, increased seed size and yield, and the improved production of metabolites [42,43]. The southern blotting hybridization of GmPLMT in transgenic A. thaliana revealed a single hybridization signal in each of the 
five positive plants with varied locations, a hybridization signal detected in the positive control, and no hybridization signal was detected in the negative controls of WT and $\mathrm{H}_{2} \mathrm{O}$ (Figure 7). These results indicated that GmPLMT was integrated into the genome of A. thaliana as a single copy, with different integration sites in different plants.

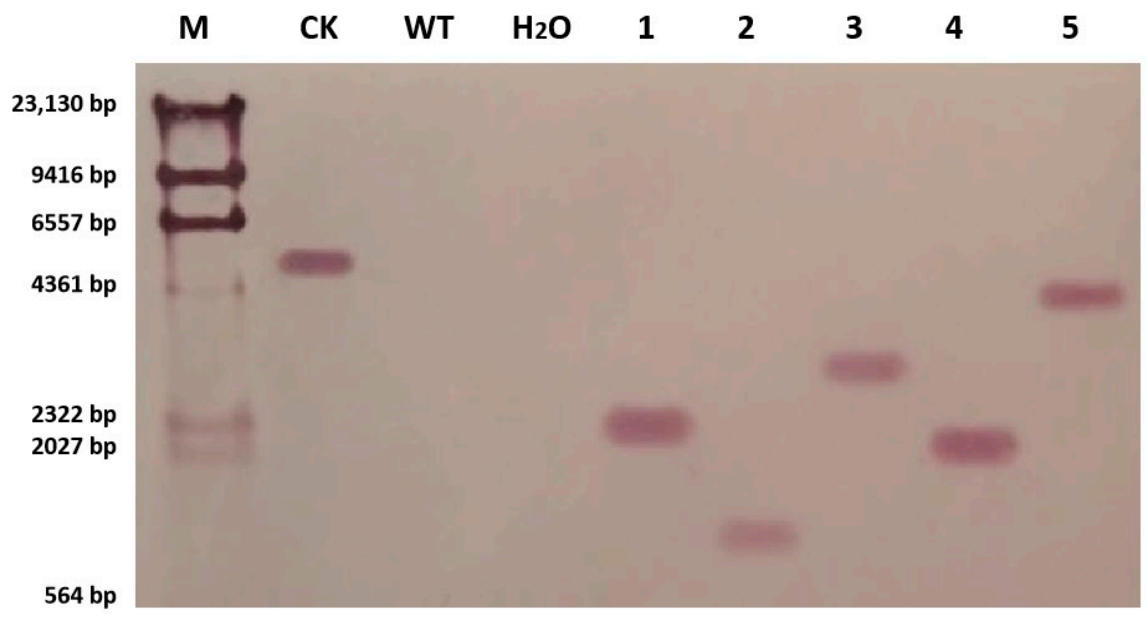

Figure 7. Southern blotting hybridization of T3 generation of transgenic Arabidopsis thaliana with GmPLMT. M, DIG-labeled $\lambda$ HindIII DNA markers; CK, positive control; WT and $\mathrm{H}_{2} \mathrm{O}$, negative controls, lanes 1-5, five random transgenic plants of $A$. thaliana with GmPLMT.

\subsection{Effects of GmPLMT Gene Expression on the Phospholipid Metabolism in Soybean}

3.3.1. Variations of GmPLMT Gene Expression in Soybean Leaves during Different Developmental Stages

The results showed that the gene expression of GmPLMT in soybean leaves varied significantly at different developmental stages. The expression levels of GmPLMT were significantly higher in both seedling and flowering stages than those in other developmental stages, decreasing to the lowest level during the maturity stage (Figure 8). These results revealed that these expression characteristics of GmPLMT were consistent with those of plant morphological growth and development, suggesting the regulatory effects of GmPLMT on plant growth and development. Flowering and podding periods are the critical growth stages for soybean, while various types of enzymes involved in biosynthetic processes of different substances could adapt to plant growth and development by promoting the expression of genes [44]. It is well known that PLMTs are the main enzymes that synthesize PtdCho in both mammalian cells and yeast [45]. The results revealed in the current study were consistent with those reported previously, showing that the activities of these enzymes have been detected in plants such as soybean, carrot, and olive [46-48].

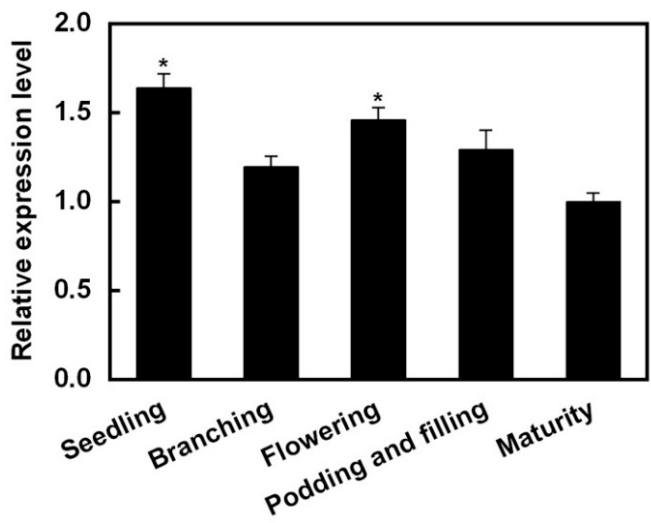

Figure 8. Relative expression of GmPLMT in soybean leaves at different developmental stages. Symbol "** indicates the significant difference at $p$-value of 0.05 in comparison to the maturity stage. 
3.3.2. Variations of GmPLMT Gene Expression in Soybean Grains at Different Stages of Maturity

The results revealed significant variations in the gene expression of GmPLMT in soybean grains with different stages of maturity (Figure 9). The expression of GmPLMT was decreased gradually from 40 to 50 days after flowering, reaching the lowest level at 50 days after flowering, and then increased gradually with the maturity of soybean seeds, reaching the highest level at 70 days after flowering, which was $72 \%$ higher than that at 35 days after flowering. At 75 days after flowering, the expression of GmPLMT was decreased again. These results indicated that the high expression levels of GmPLMT were detected during 55-70 days after flowering, which was the important growth stage for the accumulation of phospholipids during the development of grains, whereas the metabolic activities of plants were decreased after the soybean grains were fully mature, and then the expression of GmPLMT declined. These results were similar to those reported previously, showing the temporal and spatial expression patterns of genes involved in lipid metabolism in peony during seed development [49].

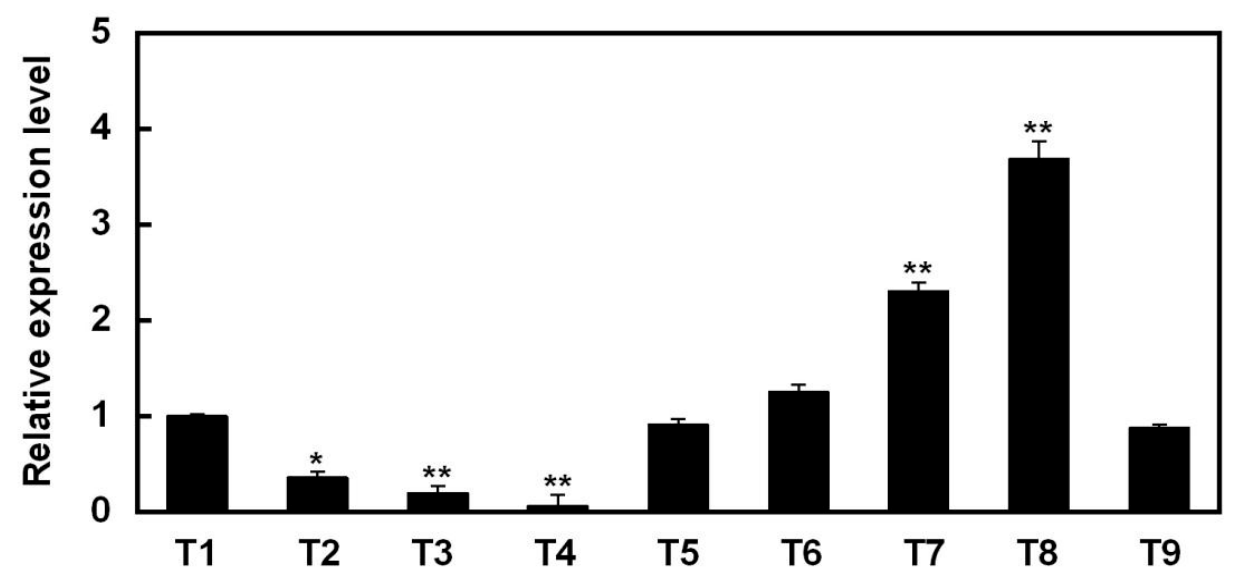

Figure 9. Relative expression of GmPLMT in soybean grains at different stages of maturity. T1-T9 represent the samples of pods collected every five days starting from the 35th day after flowering. Symbols "*" and "***" indicate significant differences at $p$ values of 0.05 and 0.01 , respectively, in comparison to $\mathrm{T} 1$.

3.3.3. Changes in the Contents of Total Phospholipids, Phosphatidylcholine, and Phosphatidylethanolamine in Soybean Grains at Different Stages of Maturity

The contents of total phospholipids, PtdCho, and PtdEtn in soybean grains at different stages of maturity were presented in Figure 10. The results showed that with the increase of soybean seed maturity, the total phospholipid contents were decreased first and then increased, with the highest content reached at 35 days after flowering and the lowest at 55 days after flowering, and the higher contents detected at 35-40 and 70-75 days after flowering. The contents of PtdCho showed a similar pattern to that of the contents of total phospholipids, i.e., decreased first and then increased. Notably, the contents of PtdEtn were not significantly different at different stages of maturity in the samples of soybean grains collected prior to 75 days after flowering, with the highest content reached at 75 days after flowering. These results revealed the evident effects of the expression of GmPLMT on the contents of the intermediate metabolites and the end products of soybean lipid metabolism. These results were consistent with those previously reported, showing that the overexpression of soybean GmPLDr gene increased the oil content and fatty acid composition in the seeds of transgenic A. thaliana [50]. 


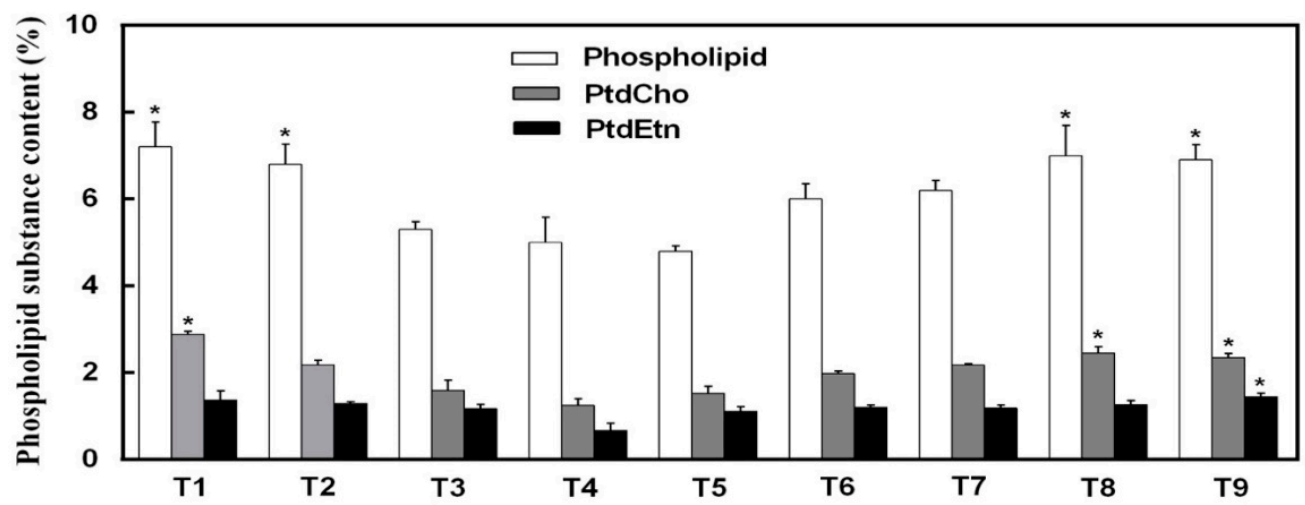

Figure 10. The contents of total phospholipids, phosphatidylcholine (PtdCho), and phosphatidylethanolamine (PtdEtn) in soybean grains of different stages of maturity. T1-T9 represents the samples of pods collected every 5 days starting from the 35th day after flowering. Symbol "*" indicates the significant difference at $p$ value of 0.05 .

3.3.4. Variations in the Contents of Fatty Acids and Crude Fats in Soybean Grains at Different Stages of Maturity

The proportions of several types of fatty acids in the total fatty acids of soybean grains at different stages of maturity were presented in Table 1 . The results showed that with the increase of soybean seed maturity, the contents of palmitic acid were increased first and then decreased; they were largely higher at 40-60 days after flowering and then decreased gradually afterward. The contents of both stearic acid and oleic acid showed similar patterns to that of palmitic acid. The contents of linoleic acid were decreased first and then increased, decreasing gradually after 35 days after flowering and reaching the highest levels at 60-70 days after flowering. The contents of linolenic acid showed a similar pattern to that of linoleic acid, an initial decrease followed by an increase, reaching the highest level at 35 days after flowering and showing largely higher levels at 65-75 days after flowering. The contents of crude fats were gradually increased at 40 days after flowering and reached the highest level at 75 days after flowering. Generally, both the lipids and proteins are the main components of soybean grains, while the fatty acids are important raw materials for the synthesis of fats. The results were consistent with those reported previously, showing that the contents of various types of fatty acids and crude fats in the maturity process were correlated with the contents of proteins in soybean seeds [51].

Table 1. The proportion of various fatty acids in the total fatty acids and the contents of crude fats in soybean grains at different stages of maturity.

\begin{tabular}{ccccccc}
\hline Sample & $\begin{array}{c}\text { Palmitic } \\
\text { Acid }\end{array}$ & $\begin{array}{c}\text { Stearic } \\
\text { Acid }\end{array}$ & Oleic Acid & $\begin{array}{c}\text { Linoleic } \\
\text { Acid }\end{array}$ & $\begin{array}{c}\text { Linolenic } \\
\text { Acid }\end{array}$ & Crude Fats \\
\hline T1 & $14.9 \pm 0.7$ & $4.4 \pm 0.2$ & $26.0 \pm 1.6$ & $42.3 \pm 2.1 *$ & $11.4 \pm 0.8^{* *}$ & $10.8 \pm 0.4$ \\
T2 & $22.0 \pm 1.1 *$ & $7.2 \pm 0.4$ & $38.2 \pm 3.8$ & $27.5 \pm 1.6$ & $3.9 \pm 0.2$ & $9.1 \pm 0.3$ \\
T3 & $24.4 \pm 1.9 *$ & $8.9 \pm 0.6$ & $42.5 \pm 3.3^{*}$ & $20.5 \pm 2.1$ & $2.4 \pm 0.2$ & $9.9 \pm 0.6$ \\
T4 & $24.1 \pm 1.2 *$ & $9.7 \pm 0.7^{*}$ & $42.4 \pm 1.7 *$ & $19.9 \pm 0.6$ & $2.3 \pm 0.1$ & $10.3 \pm 0.6$ \\
T5 & $24.2 \pm 1.4 *$ & $10.1 \pm 0.9 *$ & $44.3 \pm 2.7 *$ & $17.9 \pm 1.4$ & $1.9 \pm 0.1$ & $10.7 \pm 0.5$ \\
T6 & $22.7 \pm 1.3 *$ & $9.5 \pm 0.8^{*}$ & $44.8 \pm 2.2 *$ & $19.7 \pm 1.4$ & $1.6 \pm 0.1$ & $11.0 \pm 0.4$ \\
T7 & $12.5 \pm 1.0$ & $5.2 \pm 0.2$ & $27.1 \pm 0.6$ & $48.3 \pm 1.9 *$ & $6.1 \pm 0.4$ & $18.1 \pm 1.1^{*}$ \\
T8 & $12.8 \pm 1.2$ & $5.6 \pm 0.4$ & $23.8 \pm 1.4$ & $50.4 \pm 2.5 * *$ & $6.4 \pm 0.5$ & $18.2 \pm 0.7^{*}$ \\
T9 & $10.2 \pm 0.6$ & $4.5 \pm 0.2$ & $20.6 \pm 1.4$ & $54.4 \pm 2.2^{* *}$ & $9.2 \pm 0.6 *$ & $19.3 \pm 0.5^{*}$ \\
\hline
\end{tabular}

T1-T9 represents the samples of pods collected every 5 days starting from the 35th day after flowering. Symbols "**" and "***" indicate significant differences at $p$ values of 0.05 and 0.01 , respectively. 
3.3.5. Correlation between the Gene Expression of GmPLMT and the Contents of Lipid Metabolites in Soybean Seeds at Different Stages of Maturity

The results of the correlation analyses between GmPLMT gene expression and the contents of various types of lipid metabolites in soybean seeds at different stages of maturity showed that the expression of GmPLMT was significantly positively correlated with the contents of linoleic acid, crude fats, and PtdCho $(r=0.64,0.72$, and 0.50, respectively) and negatively correlated with the contents of palmitic acid and oleic acid $(r=-0.65$ and -0.58 , respectively) (Table 2). Furthermore, the content of PtdCho was positively correlated with that of linoleic acid $(r=0.74)$, extremely significantly correlated with those of linolenic acid and total phospholipid $(r=0.82$ and 0.93 , respectively), negatively correlated with those of palmitic acid and oleic acid $(r=-0.74$ and -0.76 , respectively), and extremely negatively correlated with that of stearic acid $(\mathrm{r}=-0.85)$. Fatty acids and ethanolamine/choline are the raw materials for the synthesis of fats and phospholipids in plants, respectively, while diacylglycerol is a commonly shared intermediate product in these synthetic pathways. Results in the current study revealed the significantly positive correlation between the expression of GmPLMT and the contents of PtdCho and two types of polyunsaturated fatty acids (i.e., linoleic acid and linolenic acid), indicating that the contents of PtdCho were regulated by gene GmPLMT in soybean grains, while gene GmPLMT may increase the phospholipid content by promoting the production of PtdCho. Studies have revealed the regulatory effects of different types of fatty acids on the metabolic genes, with the polyunsaturated fatty acids showing the most significant effect $[52,53]$, while the results of the current study were supportive of the speculations proposed and results reported previously [15].

Table 2. Correlation analysis of GmPLMT gene expression and contents of various types of lipid metabolites in soybean grains at different stages of maturity.

\begin{tabular}{|c|c|c|c|c|c|c|c|c|c|c|}
\hline $\begin{array}{l}\text { Correlation } \\
\text { Coefficient (r) }\end{array}$ & $\begin{array}{l}\text { Expression of } \\
\text { GmPLMT }\end{array}$ & $\begin{array}{l}\text { Palmitic } \\
\text { Acid }\end{array}$ & $\begin{array}{l}\text { Stearic } \\
\text { Acid }\end{array}$ & Oleic Acid & $\begin{array}{l}\text { Linoleic } \\
\text { Acid }\end{array}$ & $\begin{array}{l}\text { Linolenic } \\
\text { Acid }\end{array}$ & $\begin{array}{l}\text { Crude } \\
\text { Fat }\end{array}$ & $\begin{array}{l}\text { Total Phos- } \\
\text { pholipid }\end{array}$ & PtdCho & PtdEtn \\
\hline $\begin{array}{c}\text { Expression of } \\
\text { GmPLMT }\end{array}$ & 1.00 & & & & & & & & & \\
\hline Palmitic acid & $-0.65 *$ & 1.00 & & & & & & & & \\
\hline Stearic acid & -0.48 & $0.93 * *$ & 1.00 & & & & & & & \\
\hline Oleic acid & $-0.58 *$ & $0.98 * *$ & $0.96^{* *}$ & 1.00 & & & & & & \\
\hline Linoleic acid & $0.64 *$ & $-0.99 * *$ & $-0.94 * *$ & $-0.99^{* *}$ & 1.00 & & & & & \\
\hline Linolenic acid & 0.30 & $-0.83^{* *}$ & $-0.93 * *$ & $-0.89 * *$ & 0.84 ** & 1.00 & & & & \\
\hline Crude fat & $0.72 *$ & $-0.88^{* *}$ & $-0.67^{*}$ & $-0.81 * *$ & $0.87 * *$ & $0.50 *$ & 1.00 & & & \\
\hline Total phospholipid & 0.45 & -0.75 * & $-0.87 * *$ & $-0.79 *$ & $0.77^{*}$ & $0.8^{* *}$ & 0.45 & 1.00 & & \\
\hline PtdCho & $0.50 *$ & $-0.74 *$ & $-0.85^{* *}$ & $-0.76^{*}$ & 0.74 * & $0.82 * *$ & 0.42 & $0.93 * *$ & 1.00 & \\
\hline PtdEtn & -0.01 & $-0.62 *$ & $-0.72 *$ & $-0.70^{*}$ & $0.64^{*}$ & $0.78 *$ & 0.36 & $0.75 *$ & $0.58 *$ & 1.00 \\
\hline
\end{tabular}

Symbols "*" and "***" indicate significant differences at $p$ values of 0.05 and 0.01 , respectively. PtdCho, phosphatidylcholine; PtdEtn, phosphatidylethanolamine.

\subsection{Effects of GmPLMT Gene Expression on the Phospholipid Metabolism in Transgenic Arabidopsis thaliana}

3.4.1. Variations of GmPLMT Gene Expression in Transgenic Arabidopsis thaliana at Different Developmental Stages

The biological functions of genes in plants are generally investigated on both the molecular and genetic levels, with the heterologous expression of plant genes as an important technique based on the model plant of Arabidopsis [14]. The results of gene expression of GmPLMT during different developmental stages of transgenic A. thaliana showed that the expression reached the highest level of 2.64 at the flowering stage, followed by 2.26 and 1.66 at the four-leaf and bolting stages, respectively, which were either significantly or extremely higher than that of the maturity stage, showing the lowest expression level, i.e., $38.8 \%$ of the expression level at flowering stage in transgenic $A$. thaliana (Figure 11). These results indicated that the gene GmPLMT was efficiently expressed in transgenic $A$. thaliana, showing the highest expression level during the flowering stage. In general, plant growth and development are mainly determined by the genes controlling the traits and the environment. Evidently, the GmPLMT gene showed consistent expression patterns in both 
the transgenic plants of $A$. thaliana and soybeans in different developmental stages, while during the maturity period with the completion of material storage, the enzyme activities were decreased to the lowest level. Therefore, it was speculated that the GMPLMT gene plays an important role in plant growth and development. Further studies are needed to verify the discoveries revealed in the current study.

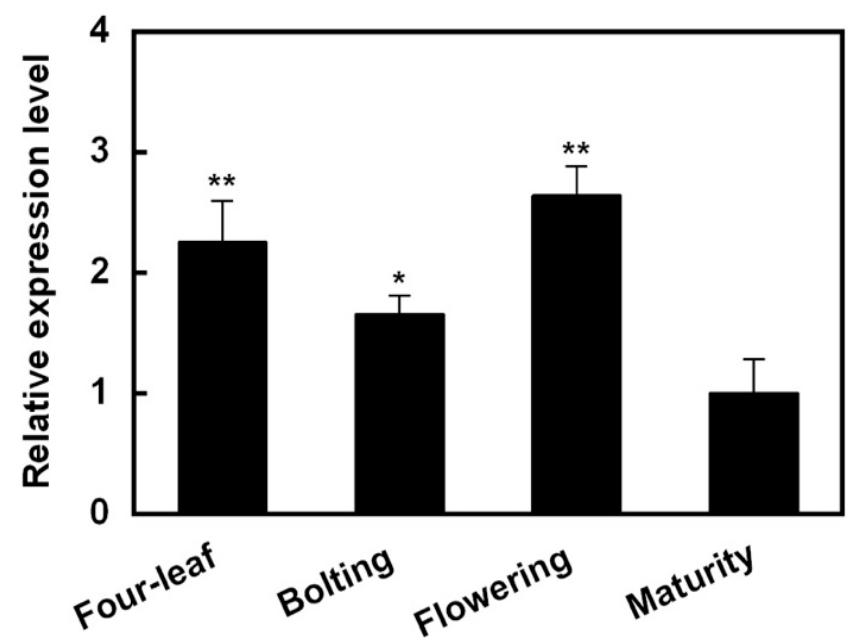

Figure 11. Relative expression of GmPLMT in transgenic Arabidopsis thaliana at different developmental stages. Symbols “*” and “*** indicate significant differences at $p$ values of 0.05 and 0.01 , respectively.

3.4.2. Variations of the Physiological and Biochemical Indices Related to Phospholipid Metabolism in Transgenic Arabidopsis thaliana Seeds with GmPLMT

The variations of the phospholipid metabolic products in transgenic $A$. thaliana seeds with GmPLMT are presented in Figure 12. The results showed that the contents of the total phospholipids in transgenic $A$. thaliana were increased significantly to 2.02 times higher than that of WT plants. The contents of PtdCho in transgenic plants accounted for $9.07 \%$ and $10.3 \%$ of those of the total phospholipids in the WT and the transgenic $A$. thaliana, respectively. Although the content of PtdEtn in transgenic A. thaliana was 1.36 times higher than that of WT plants, the difference was not statistically significant. These results showed that overexpression of GmPLMT increased the contents of both the total phospholipids and PtdCho in transgenic A. thaliana. These results were consistent with those reported previously, showing that PLMTs were involved in the synthesis of PtdCho $[54,55]$.

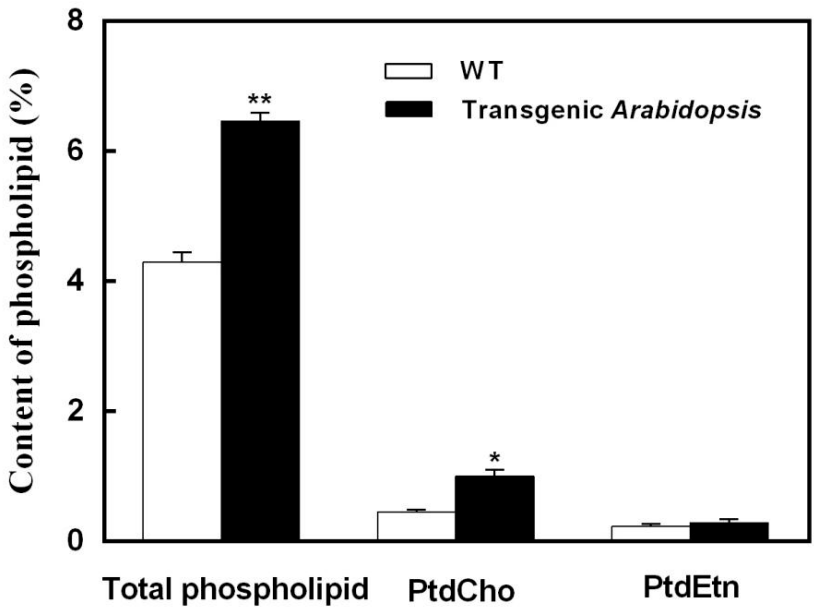

Figure 12. Contents of total phospholipids, phosphatidylcholine (PtdCho), and phosphatidylethanolamine (PtdEtn) in seeds of wild type (WT) and transgenic plants of Arabidopsis thaliana with GmPLMT. Symbols "**" and "***" indicate significant differences at $p$ values of 0.05 and 0.01 , respectively. 
3.4.3. Variations of Physiological and Biochemical Indices Related to Lipid Metabolism in Transgenic Arabidopsis thaliana Seeds with GmPLMT

The contents of crude fats and several types of fatty acids in the total fatty acids in transgenic A. thaliana seeds with GmPLMT were shown in Figure 13. These results revealed that the contents of both linoleic acid and linolenic acid in the total fatty acids were significantly higher than those of WT plants of $A$. thaliana, increasing by $34.5 \%$ and $29.3 \%$, respectively. Although the contents of palmitic acid, stearic acid, and oleic acid were lower than those of WT plants, the differences were not statistically significant. The contents of crude fats in seeds of WT plants of $A$. thaliana were 2.27 times higher than those of transgenic plants $(p<0.01)$. Similarly, previous studies have shown that both seed mass and oil content were increased in transgenic $A$. thaliana by the overexpression of the wri1-like gene from Brassica napus [56]. These results indicated that the increased expression of GmPLMT significantly improved the contents of polyunsaturated fatty acids in the seeds of transgenic plants, whereas the synthesis of crude fats was decreased by the overexpression of GmPLMT.

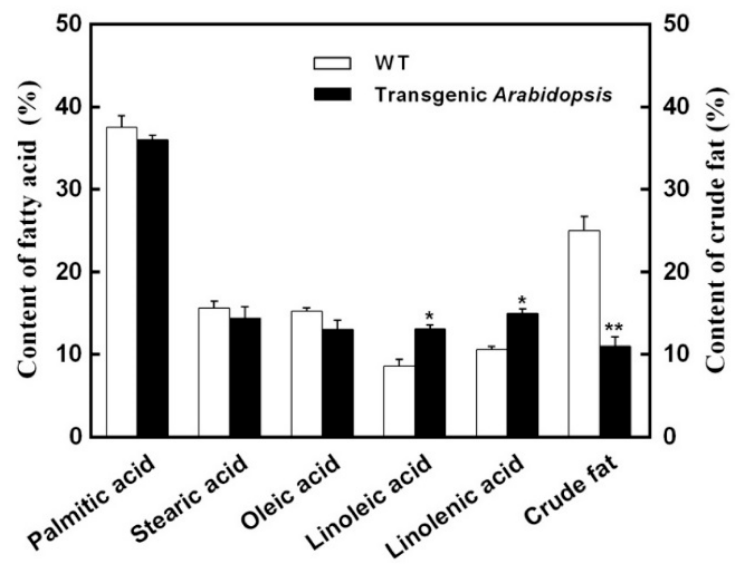

Figure 13. Contents of several types of fatty acids in the total fatty acids and the crude fats in seeds of wild type (WT) and the transgenic plants of Arabidopsis thaliana with GmPLMT. Symbols "** and “**" indicate significant differences at $p$ values of 0.05 and 0.01 , respectively.

\section{Conclusions}

Compared with WT plants, the expression levels of GmPLMT in transgenic plants of A. thaliana were increased, the contents of total phospholipid and PtdCho were increased significantly, the contents of linoleic acid and linolenic acid were significantly up-regulated, and the contents of crude fats were decreased significantly. It was speculated that the heterologous expression of GmPLMT in A. thaliana altered the dynamic process of lipid metabolism, promoting the synthesis of phospholipids and reducing the fat synthesis, ultimately leading to fatty acid accumulation and significantly increasing the contents of PtdCho and the total phospholipids in transgenic A. thaliana. The overexpression of $G m-$ PLMT increased not only the contents of PtdCho, but also the contents of polyunsaturated fatty acids in plant seeds. These results provide novel experimental evidence to further enhance the understanding of the biosynthetic pathway of PtdCho in legumes. The current study provides the experimental foundation for further exploring the specific pathways of lipid synthesis and its regulation in plants, and identifies the candidate gene GmPLMT for future improvement of soybean quality based on genetic engineering and the molecular breeding of soybean.

Author Contributions: Conceptualization, Z.C. and X.C.; methodology, Z.C. and X.C.; software, Z.C.; validation, Y.W., Y.C., X.Y. and S.W.; formal analysis, Z.C., S.W., T.Y. and Y.Z.; investigation, X.C.; resources, X.C.; data curation, X.C.; writing-original draft preparation, Y.Z. and X.C.; writing-review and editing, Y.Z. and X.C.; visualization, T.Y.; supervision, X.C.; project administration, X.C.; funding acquisition, X.C. All authors have read and agreed to the published version of the manuscript. 
Funding: This work was funded by the Natural Science Foundation of Jilin Province (20210101023JC) and the Science and Technology Development Plan Project of Jilin Province (20210203019SF). The APC was funded by X.C.

Conflicts of Interest: The authors declare no conflict of interest.

\section{References}

1. Liu, S.; Liu, N.; Lu, H.J.; Zhu, L.Z. Disturbed phospholipid metabolism by three polycyclic aromatic hydrocarbons in Oryza sativa. Environ. Pollut. 2021, 283, 117073. [CrossRef]

2. Kim, I.S.; Kim, C.H.; Yang, W.S. Physiologically active molecules and functional properties of soybeans in human healthA current perspective. Int. J. Mol. Sci. 2021, 22, 4054. [CrossRef]

3. Asano, T.; Hayashi, N.; Kobayashi, M.; Aoki, N.; Miyao, A.; Mitsuhara, I.; Ichikawa, H.; Komatsu, S.; Hirochika, H.; Kikuchi, S.; et al. A rice calcium-dependent protein kinase oscpk12 oppositely modulates salt-stress tolerance and blast disease resistance. Plant J. 2015, 69, 26-36. [CrossRef] [PubMed]

4. Oke, M.; Jacob, J.K.; Paliyath, G. Effect of soy lecithin in enhancing fruit juice/sauce quality. Food Res. Int. 2010, 43, 232-240. [CrossRef]

5. Jost, R.; Berkowitz, O.; Shaw, J.; Masel, J. Biochemical characterization of two wheat phosphoethanolamine N-methyltransferase isoforms with different sensitivities to inhibition by phosphatidic acid. J. Biol. Chem. 2009, 284, 31962-31971. [CrossRef] [PubMed]

6. Zhang, X.H.; Zhao, C.; Seleznev, K.; Song, K.; Manfredi, J.J.; Ma, Z.A. Disruption of G1-phase phospholipid turnover by inhibition of $\mathrm{Ca}^{2+}$-independent phospholipase A2 induces a p53-dependent cell-cycle arrest in G1 phase. J. Cell Sci. 2006, 119, 1005-1015. [CrossRef] [PubMed]

7. Gu, X.; Beardslee, T.; Zeece, M.; Sarath, G.; Markwell, J. Identifification of IgE-binding proteins in soy lecithin. Int. Arch. Allergy Immunol. 2001, 126, 218-225. [CrossRef] [PubMed]

8. Chen, W.H.; Salari, H.; Taylor, M.C.; Jost, R.; Berkowitz, O.; Barrow, R.; Qiu, D.Y.; Branco, R.; Maslea, J. NMT1 and NMT3 N-Methyltransferase activity is critical to lipid homeostasis, morphogenesis, and reproduction. Plant Physiol. 2018, 177, 1605-1628. [CrossRef]

9. Yun, T.L.; Mohammed, O.; Ya, J.Q.; Jia, C.S.; Shu, Y.L.; Jun, S.; Zhong, W.C.; Bin, X. Extraction of oat lipids and phospholipids using subcritical propane and dimethyl ether: Experimental data and modeling. Eur. J. Lipid Sci. Technol. 2021, 123, 2000092.

10. Singleton, J.A.; Ruan, M.; Sanford, J.H.; Haney, C.A.; Stikeleather, L.F. Separation and characterization of peanut phospholipid molecular species using high-performance liquid chromatography and fast atom bombardment mass spectrometry. J. Am. Oil. Chem. Soc. 1999, 76, 49-56. [CrossRef]

11. Abhijit, C. Phospholipid asymmetry in biological membranes: Is the role of phosphatidylethanolamine underappreciated? J. Membrane Biol. 2021, 254, 127-132.

12. Tsutomu, K.; Satoshi, Y. Characterization of the methyltransferases in the yeast phosphatidylethanolamine methylation pathway by selective gene disruption. Eur. J. Biochem. 1989, 185, 243-251.

13. Margaret, I.K.; Susan, A.H. The phospholipid methyltransferases in yeast. Biochim. Biophys. Acta 1997, 1348, $134-141$.

14. Bolognese, C.P.; McGraw, P. The isolation and characterization in yeast of a gene for arabidopsis S-Adenosylmethionine: Phospho-Ethanolamine N-Methyltransferase. Plant Physiol. 2000, 124, 1800-1813. [CrossRef] [PubMed]

15. Keogh, M.R.; Courtney, P.D.; Kinney, A.J.; Dewey, R.E. Functional characterization of phospholipid N-methyltransferases from Arabidopsis and soybean. J. Biol. Chem. 2009, 284, 15439-15447. [CrossRef]

16. Liu, Y.C.; Lin, Y.C.; Kanehara1, K.; Nakamura1, Y. A pair of phospho-base methyltransferases important for phosphatidylcholine biosynthesis in Arabidopsis. Plant J. 2018, 96, 1064-1075. [CrossRef]

17. Ji, X.M.; Wu, X.Y.; Chen, W.; Yuan, Q.H.; Shen, Y.X.; Chi, Y.J. Cloning and functional identification of phosphoethanolamine methyltransferase in soybean (Glycine max). Front. Plant Sci. 2021, 12, 612158. [CrossRef]

18. McNeil, S.D.; Nuccio, M.L.; Ziemak, M.J.; Hanson, A.D. Enhanced synthesis of choline and glycine betaine in transgenic tobacco plants that overexpress phosphoethanolamine N-methyltrasferase. Proc. Natl. Acad. Sci. USA 2001, 98, 10001-10005. [CrossRef] [PubMed]

19. Sakamoto, A.; Valverde, R.; Chen, T.H.; Murata, N. Transformation of Arabidopsis with the codA gene for choline oxidase enhances freezing tolerance of plants. Plant J. 2000, 22, 449-453. [CrossRef]

20. Cui, X.Y.; Wang, Y.; Guo, J.X. Osmotic regulation of betaine content in Leymus chinensis under saline-alkali stress and cloning and expression of betaine aldehyde dehydrogenase (BADH) gene. Chem. Res. Chin. Univ. 2008, 24, 204-209. [CrossRef]

21. Qin, F.; Shinozaki, K.; Yamaguchi-Shinozaki, K. Achievements and challenges in understanding plant abiotic stress responses and tolerance. Plant Cell Physiol. 2011, 52, 1569. [CrossRef]

22. Wang, S.; Xu, H.X.; Zhang, J.F.; Li, H.L.; Yuan, X.S.; Cui, X.Y. Cloning of soybean PLMT gene and expression analysis of it under saline-alkaline stress. Mol. Plant Breed. 2018, 16, 4824-4828.

23. Gasteiger, E.; Gattiker, A.; Hoogland, C.; Ivanyi, I.; Appel, R.D. ExPASy: The proteomics server for in-depth protein knowledge and analysis. Nucl. Acid. Res. 2003, 31, 3784-3788. [CrossRef]

24. Geourjon, C.; Deleage, G. SOPAM: Significant improvements in protein secondary structure prediction by consensus prediction from multiple alignments. Comp. Appl. Biosci. 1995, 11, 681-684. 
25. Bendtsen, J.D.; Nielsen, H.; von Heijne, G.; Brunak, S. Improve prediction of signal peptides: SignalP3.0. J. Mol. Biol. 2004, 340, 783-785. [CrossRef] [PubMed]

26. Spyropoulos, I.C.; Liakopoulos, T.D.; Bagos, P.G.; Hamodrakas, S.J. TMRPres2D: High quality visual representation of transmembrane protein models. Bioinformatics 2004, 20, 3258-3260. [CrossRef] [PubMed]

27. Kessler, B.; Lorenzo, V.D.; Timmis, K.N. A general system to integrate lacZ fusions into the chromosomes of gram-negative eubacteria: Regulation of the Pm promoter of the TOL plasmid studied with all controlling elements in monocopy. Mol. Gen. Genet. 1992, 233, 293. [CrossRef] [PubMed]

28. Shi, L.; Miao, L.J.; Qi, F.Y.; Zhang, Z.X.; Gao, W.; Sun, Z.Q.; Huang, B.Y.; Dong, W.Z.; Tang, F.S.; Zhang, X.Y. Cloning and functional analysis of peanut $\Delta$ 9-stearoyl-acyl carrier protein desaturase promoter. Acta Agron. Sin. 2016, 11, 1629-1637. [CrossRef]

29. Worrall, D. Southern analysis of transgenic tobacco plants. Methods Mol. Biol. 1998, 81, 425-436. [PubMed]

30. Zastrow-Hayes, G.M.; Lin, H.N.; Sigmund, A.L.; Hoffman, J.L.; Alarcon, C.M.; Hayes, K.R.; Richmond, T.A.; Jeddeloh, J.A.; May, G.D.; Beatty, M.K. Southern-by-Sequencing: A robust screening approach for molecular characterization of genetically modified crops. Plant Genome 2015, 8, 1-15. [CrossRef]

31. Thomas, D.S.; Kenneth, J.L. Analyzing real-time PCR data by the comparative CT method. Nature 2008, 6, 1101-1108.

32. Gustavsson, L. Densitometric quantification of individual phospholipids. Improvement and evaluation of a method using molybdenum blue reagent for detection. J. Chromatogr. 1986, 375, 255-266. [CrossRef]

33. Wang, C.T. The Studies on Preparation of High Content Phosphatidylcholine Phospholipid from Powerded Phosphatide; Henan University of Technology: Luoyang, China, 2010.

34. Zheng, Y.Z.; Gai, J.Y.; Lu, W.G.; Li, W.D.; Zhou, R.B.; Tian, S.J. QTL mapping for fat and fatty acid composition contents in soybean. Acta Agron. Sin. 2006, 32, 1823-1830.

35. Kanipes, M.I.; Hill, J.E.; Henry, S.A. The Schizosaccharomyces pombe cho1+ gene encodes a phospholipid methyltransferase. Genetics 1998, 2, 553-562. [CrossRef] [PubMed]

36. Wlodarski, T.; Kutner, J.; Towpik, J.; Knizewski, L.; Rychlewski, L.; Kudlicki, A.; Rowicka, M.; Dziembowski, A.; Ginalski, K. Comprehensive structural and substrate specificity classification of the Saccharomyces cerevisiae methyltransferome. PLoS ONE 2011, 6, 23168. [CrossRef] [PubMed]

37. Kozbial, P.Z.; Mushegian, A.R. Natural history of S-adenosylmethionine-binding proteins. BMC Struct. Biol. 2005, 5, 19. [CrossRef]

38. Gaynor, P.M.; Carman, G.M. Phosphatidylethanolamine methyltransferase and phospholipid methyltransferase activities from Saccharomyces cerevisiae. Enzymological and kinetic properties. Biochim. Biophys. Acta 1990, 1045, 156-163. [CrossRef]

39. Ingrosso, D.; Fowler, A.V.; Bleibaum, J.; Clarke, S. Sequence of the D-aspartyl/L-isoaspartyl protein methyltransferase from human erythrocytes: Common sequence motifs for protein, DNA, RNA and small molecule S-adenosylmethionine-dependent methyltransferases. J. Biol. Chem. 1989, 264, 20131-20139. [CrossRef]

40. Schluckebier, G.; O'Gara, M.; Saenger, W.; Cheng, X. Universal catalytic domain structure of AdoMet-dependent methyltransferases. J. Mol. Biol. 1995, 247, 16-20. [CrossRef] [PubMed]

41. Schubert, H.L.; Blumenthal, R.M.; Cheng, X. Many paths to methyltransfer: A chronicle of convergence. Trends Biochem. Sci. 2003, 28, 329-335. [CrossRef]

42. Zhang, Y.J.; Yu, L.; Yung, K.F.; Leung, D.Y.C.; Sun, F.; Lim, B.L. Over-expression of AtPAP2 in Camelina sativa leads to faster plant growth and higher seed yield. Biotechnol. Biofuels 2012, 5, 19. [CrossRef] [PubMed]

43. Feng, S.; Suen, P.K.; Zhang, Y.J.; Liang, C.; Carrie, C.; Whelan, J.; Ward, J.L.; Hawkins, N.D.; Jiang, L.W.; Lim, B.L. A dual-targeted purple acid phosphatase in Arabidopsis thaliana moderates carbon metabolism and its overexpression leads to faster plant growth and higher seed yield. New Phytol. 2012, 19, 206-219.

44. Yang, X.; Li, X.; Shan, J.M.; Li, Y.H.; Zhang, Y.T.; Wang, Y.H.; Li, W.B.; Zhao, L. Overexpression of GmGAMYB accelerates the transition to flowering and increases plant height in soybean. Front. Plant Sci. 2021, 12, 667242. [CrossRef]

45. Vance, D.E. Physiological roles of phosphatidylethanolamine N-methyltransferase. Biochim. Biophys. Acta 2013, $1831,626-632$. [CrossRef] [PubMed]

46. Datko, A.H.; Mudd, S.H. Phosphatidylcholine synthesis: Differing patterns in soybean and carrot. Plant Physiol. 1988, 88, 854-861. [CrossRef] [PubMed]

47. Datko, A.H.; Mudd, S.H. Enzymes of phosphatidylcholine synthesis in lemna, soybean, and carrot. Plant Physiol. 1988, 88, 1338-1348. [CrossRef] [PubMed]

48. Williams, M.; Harwood, J.L. Alternative pathways for phosphatidylcholine synthesis in olive (Olea europaea L.) callus cultures. Biochem. J. 1994, 304, 463-468. [CrossRef]

49. Li, C.; Hu, L.Z.; Que, B.B.; Hu, Y.R.; Guo, Y.Y.; Zhang, M.H.; Wang, Z.N.; Wang, X.Q.; Liu, H.Z.; Wang, J.S.; et al. Expression profiles of genes involved in fatty acid and lipid biosynthesis in developing seeds of Paeonia ostii. Genes Genom. 2021, 43, 885-896. [CrossRef] [PubMed]

50. Bai, Y.; Guang, Q.J.; Jing, Z.; Shu, X.L.; Rong, R.B.; Jiang, Z.Z.; Qian, R.J.; Qun, Z.; Wen, H.Z. Overexpression of soybean GmPLD $\gamma$ enhances seed oil content and modulates fatty acid composition in transgenic Arabidopsis. Plant Sci. 2020, $290,110298$. [CrossRef] [PubMed]

51. Wang, J.; Zhou, P.F.; Shi, X.L.; Yang, N.; Yan, L.; Zhao, Q.S.; Yang, C.Y.; Guan, Y.F. Primary metabolite contents are correlated with seed protein and oil traits in near-isogenic lines of soybean. Crop J. 2019, 7, 651-659. [CrossRef] 
52. Pham, A.T.; Lee, J.D.; Shannon, J.G.; Bilyeu, K.D. Mutant alleles of FAD2-1A and FAD2-1B combine to produce soybeans with the high oleic acid seed oil trait. BMC Plant Biol. 2010, 10, 195. [CrossRef] [PubMed]

53. Wang, X.Z.; Jiang, G.L.; Green, M.; Scott, R.A.; Hyten, D.L.; Cregan, P.B. Quantitative trait locus analysis of saturated fatty acids in a population of recombinant inbred lines of soybean. Mol. Breed. 2014, 33, 281-296. [CrossRef]

54. Nakamura, Y. Headgroup biosynthesis of phosphatidylcholine and phosphatidylethanolamine in seed plants. Prog. Lipid Res. 2021, 82, 101091. [CrossRef]

55. Boumann, H.A.; Chin, P.T.; Heck, A.J.; De Kruijff, B.; De Kroon, A.I. The yeast phospholipid N-methyltransferases catalyzing the synthesis of phosphatidylcholine preferentially convert di-C16:1 substrates both in vivo and in vitro. J. Biol. Chem. 2004, 279, 40314-40319. [CrossRef] [PubMed]

56. Liu, J.; Hua, W.; Zhan, G.M.; Wei, F.; Wang, X.F.; Liu, G.H.; Wang, H.Z. Increasing seed mass and oil content in transgenic Arabidopsis by the overexpression of wri1-like gene from Brassica napus. Plant Physiol Bioch. 2010, 48, 9-15. [CrossRef] [PubMed] 